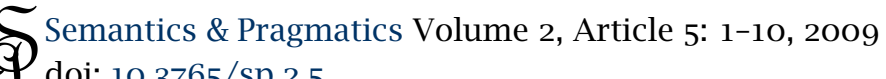

O doi: $10.3765 /$ sp.2.5

\title{
Free choice for all: a response to Emmanuel Chemla*
}

\author{
Bart Geurts \\ University of Nijmegen \\ Nausicaa Pouscoulous \\ University College London
}

Received 2009-08-25 / First Decision 2009-09-21 / Revised 2009-09-24 / Accepted 2009-10-07 / Published 2009-10-09

\begin{abstract}
Chemla (2009) presents experimental data purporting to show that speakers' intuitions about so-called "embedded implicatures" cause trouble for globalist and localist theories alike. We explain, to begin with, that the way Chemla frames the debate between localists and globalists fails to do justice to the latter. Then we turn to his experimental data, and argue that, while of half of them strengthen our own case against localism (Geurts \& Pouscoulous 2009), the other half do not jeopardize the globalist view, as Chemla claims they do.
\end{abstract}

Keywords: Free choice, Emmanuel Chemla, Exhaustivity

\section{Introduction}

Formal theories of Gricean reasoning seem to have the same ontological status as selfless bankers and honest lawyers: they don't exist and it may well be that, as a matter of metaphysical necessity, they could not exist, either. The troubles haunting the formalization of Gricean pragmatics already prompted Gazdar to comment that

[...] the sheer difficulty of formalizing some of Grice's notions (for example, "relevance") probably makes parts of his enterprise unusable for linguists at the present time. Furthermore, those parts that are usable have to be so restrictively defined-as in this book-that much of the power and generality of Grice's discussion is lost. But not to stick to formalist methodology in an area like this can only lead out of linguistics and into literary criticism. (Gazdar 1979: 53-54)

* Chemla, Emmanuel. 2009. Universal implicatures and free choice effects: Experimental data. Semantics and Pragmatics 2(2). 1-33. doi:10.3765/sp.2.2.

(C)2009 Bart Geurts \& Nausicaa Pouscoulous

This is an open-access article distributed under the terms of a Creative Commons NonCommercial License (creativecommons.org/licenses/by-nc/3.o). 
Gazdar's caustic remarks clearly imply that his own formal theory fails to do justice to Grice's notion of conversational implicature. Theories of a younger vintage, even if they improve on Gazdar's technically as well as empirically, don't do much better in this respect.

Building on Groenendijk \& Stokhof's (1984) joint dissertation, Schulz \& van Rooij (2006) and Spector (2006) study an "exhaustivity operator" that allows them to replicate a certain range of quantity implicatures. To explain, consider the following example. Inspector Ambrose, who is investigating a murder case, informs constable Bacon that:

(1) Many of the testimonies are false.

Now, according to the orthodox Gricean account, Bacon is entitled to reason as follows:

i. Instead of saying (1) Ambrose could have said: "All the testimonies are false." Why didn't he do so?

ii. Presumably, because it is not the case that he believes all testimonies are false.

iii. Ambrose seems to be well-informed, so he probably knows whether or not all testimonies are false.

iv. Hence, for all Ambrose knows, not all testimonies are false.

On this analysis, Bacon first derives a weak implicature, $\neg \mathrm{BEL}_{\mathrm{A}}$ (all the testimonies are false), which is strengthened to $\operatorname{BEL}_{A}(\neg$ (all the testimonies are false)) on the assumption that Ambrose is well-informed, which is to say that either $\mathrm{BEL}_{\mathrm{A}}$ (all the testimonies are false) or $\mathrm{BEL}_{\mathrm{A}}(\neg$ (all the testimonies are false)). It depends on the context whether or not this well-informedness assumption holds, and if it doesn't the weak implicature will not be strengthened.

As it turns out, applying the exhaustivity operator to (the proposition expressed by) (1) yields an interpretation that entails the strong implicature. In other words, the well-informedness assumption is, in effect, built into the notion of exhaustification; weak implicatures cannot be captured this way. This is one of the main reasons why the exhaustivity operator is no substitute for Gricean reasoning; it merely provides a way of characterizing a particular class of quantity implicatures. While this is surely interesting and useful, it can hardly be claimed to be a formalization of Gricean reasoning, nor do 
Free choice for all: a response to Emmanuel Chemla

Schulz and van Rooij or Spector claim that it is (Spector 2007, in particular, is quite explicit on this point).

Groenendijk and Stokhof's exhaustivity operator was inducted into syntax by Chierchia (2006) and Fox (2007), who named it "O" and revamped it into a covert element that can be inserted into the parse tree ad libitum, thus giving rise to "embedded implicatures". Formally speaking, this boosts the predictive power of the machinery developed by Groenendijk and Stokhof and their successors, but it doesn't count a formalization of Gricean pragmatics, either, for the simple reason that Chierchia, Fox, et al.'s project doesn't have anything to do with pragmatics; their enterprise is a syntactic one. And besides, their “embedded implicatures” aren't implicatures, but truthconditional enrichments.

\section{Chemla's formal framework}

What does all this have to do with Chemla's (2009) paper? It is the backdrop for the formal framework he adopts, which conveniently allows him to abstract away from most of the details of the ongoing debate about quantity implicatures, but also yields a somewhat lopsided view of the key issues, by creating the impression that, according to all parties, quantity implicatures are to be derived by means of an exhaustivity operator, and that the controversy is just about what constraints the deployment of $\mathbf{O}$ is subject to, with "globalists" arguing that the operator may only be prefixed to complete sentences, while "localists" favour a more liberal use of $\mathbf{O}$. However, this is to view the debate through a localist lens, and to force the Gricean approach into a formal straightjacket. What the discussion really is about is whether some quantity implicatures are in fact implicatures or not. According to localists like Chierchia and Fox, strong (but not weak) scalar inferences and free choice inferences are not pragmatic in nature; rather, they are alleged to be conventional aspects of meaning (hence not really inferences at all), which are generated in the grammar. It's pragmatics against syntax, and not just a matter of where to put your Os.

The procrustean aspect of Chemla's theoretical framework is particularly notable, and very much implicit, in his discussion of free choice inferences (pp. 9-11).

(2) You can have a daiquiri or a piña colada.

$\leadsto$ You can have a daiquiri.

$\leadsto$ You can have a piña colada. 
Chemla says that the free choice interpretation of (2) may be captured by prefixing the sentence with a single $\mathbf{O}$-operator, thus implying that a "globalist" treatment of free choice can be had practically for free without going beyond the confines of the $\mathbf{O}$-based framework he adopts. However, as Chemla concedes in his footnote 10, this analysis requires a drastic reinterpretation of the O-operator, which shouldn't come as a surprise, since Fox (2007) has shown that, on a more standard interpretation of $\mathbf{O}$, recursive exhaustification is needed to capture free choice; that is to say, (2) will have to be parsed as $\mathbf{O O}[y o u$ can have a daiquiri or a piña colada] in order to obtain the right result. Hence, what Chemla is suggesting, in effect, is that we should define a new operator, call it $\mathbf{O}$ *, which iterates $\mathbf{O}$ until no further "implicatures" are generated. Using this operator, he says, (2) can be analysed "globalistically" as $\mathbf{O}$ *[you can have a daiquiri or a piña colada]. While technically speaking, this surely counts as a globalist analysis, we are less than convinced that it qualifies as a pragmatic one. Defining an operator is one thing; providing a principled pragmatic explanation is quite another.

\section{Embedded "some"}

Having expressed our worries about the way Chemla frames the discussion of his experimental data, let us now turn to the data themselves, starting with embedded scalars:

(3) a. Paul passed most of his exams $\leadsto$ He didn't pass them all.

b. Everybody passed most of their exams $\sim$ Nobody passed them all.

(4) a. Paul didn't pass all his exams $\sim$ He passed some of them.

b. Nobody passed all their exams $\sim$ Everybody passed some of them.

Chemla's main finding is that, whereas his participants judged that the ainferences are quite robust, they felt that the b-inferences were significantly weaker. Chemla concludes, and we concur, that this outcome agrees with a globalist view on scalar implicatures, and speaks against a localist approach.

Chemla's conclusion is strengthened by the fact that his data are line with what we found in our experiments (Geurts \& Pouscoulous 2009). In our Experiment 1, we found that whereas inferences similar to (3a) were endorsed $93 \%$ of the time, inferences like (3b) were endorsed only $27 \%$ of the time. The main differences between Chemla's experiment and ours are that we used "some" instead of "most" and that we asked for yes/no judgments, 
Free choice for all: a response to Emmanuel Chemla

while Chemla's subjects had to rate arguments on a scale. Despite these differences, the outcome is the same in both cases.

The point is driven home more forcefully by the verification tasks we used in our Experiments 3 and 4, which between them produced one participant who on one trial gave a response that was in line with localist predictions; none of the remaining trials with "every" provided evidence for a localist construal of the embedded scalar, and the same was true of the "more than one" items. Taken together, then, no less than four distinct experimental paradigms unanimously indicate that localist predictions about quantified statements are wrong. In our opinion, this should suffice to quell Chierchia, Fox \& Spector's (to appear) "empirical generalization" that scalar inferences occur "systematically and freely in arbitrarily embedded positions".

There is one further point about this part of Chemla's study that we feel bears emphasising. In our article, we argued at length, and provided experimental evidence for our claim, that the experimental paradigm we used in Experiment 1 was biased: when asked whether (3a) implies (3b) for example, people will tend to say yes for reasons that have nothing to do with implicatures per se. Consequently, the mere fact that, in our experiment, participants endorsed a similar inference $27 \%$ of the time is of no interest in itself. In particular, this fact does not provide support for a suitably weakened version of localism. As Chemla notes in passing (p. 14) the same holds for his experimental paradigm, but in fact it holds with a vengeance: Chemla asked his participants to indicate how strongly one proposition suggests another, using a scale ranging from "weak" to "strong". It is hard to say how participants may have interpreted this task, but it does seem to presuppose that there is an implication, even if it is weak. Be this as it may, we should like to stress that the only thing that matters, in Chemla's experiment as well as ours, is the contrast between conditions. This contrast falsifies localist predictions.

\section{Free choice}

In the second half of Chemla's study, participants were presented with the following arguments:

(5) a. Marie is allowed to take Algebra or Literature.

$\leadsto$ She can choose which of the two she will take.

b. Everybody is allowed to take Algebra or Literature.

$\leadsto$ Everybody can choose which of the two they will take. 
(6) a. Marie doesn't have to take Algebra and Literature.

$\leadsto$ She can choose which of the two she will take.

b. Nobody has to take Algebra and Literature.

$\leadsto$ Everybody can choose which of the two they will take.

Now the pattern of responses was strikingly different from what we had before: in neither case was there a significant difference between the aand the b-inferences, and whereas Chemla's participants judged that both inferences in (5) were highly robust, they felt that the two inferences in (6) were much weaker. According to Chemla, these results are problematic for localists as well as for globalists, but more so for the latter than the former. On Chemla's construal of the globalist view, it predicts the same pattern of responses for (5)-(6) as for (3)-(4), and his data falsify these predictions for positive and negative statements alike. By contrast, localist theories at least get the positive cases right, though they are disconfirmed by the negative ones.

We believe that these conclusions are premature, for two main reasons. First, we should like to note that the intended interpretation of the target sentences in (6a) and (6b) requires contrastive stress on "and." In isolation, (6a) is easily understood as implying that Marie has the option of taking neither Algebra nor Literature, if she so wishes (Szabolcsi \& Haddican 2004). This reading is inconsistent with the context in which Chemla presented (6a) and therefore this sentence is arguably infelicitous: it should have said that "Marie doesn't have to take Algebra AND Literature." The same holds for (6b) mutatis mutandis. While this is already a potential confound in itself, it creates a further problem, which may be more serious. If it is true, as we are suggesting, that the sentences in (6) require a marked interpretation of the conjunction, then all bets are off, because marked construals are highly context-dependent and vary to such a degree that it puts them squarely beyond the scope of localist and globalist theories alike:

(7) Julius didn't have fish AND strawberry pie: he had fish wITH strawberry pie.

Hence, the fact that globalist and localist theories make false predictions about (6a) and (6b) should not be held against them (see Geurts to appear for further discussion).

This leaves us with the fact that Chemla's participants agreed that both inferences in (5) are quite plausible. Chemla says that this datum agrees with 
Free choice for all: a response to Emmanuel Chemla

the localist approach, but contravenes globalist predictions. We disagree with both claims. First, we are concerned about the generality of Chemla's result. As is well known, free choice inferences are not restricted to deontic modals, but occur with other modals as well:

(8) I can write a haiku or play the Moonlight Sonata.

$\leadsto$ I can write a haiku.

$\leadsto$ I can play the Moonlight Sonata.

(9) If things had turned out differently, I could have been a banker or a lawyer.

$\sim$ I could have been a banker.

$\sim$ I could have been a lawyer.

What's more, as observed independently by Eckardt (2007), Fox (2007), and Klinedinst (2007), free choice inferences don't even require a modal environment:

(10) Some of the guests ordered scrambled eggs or an omelet.

$\leadsto$ Some of the guests ordered scrambled eggs.

$\leadsto$ Some of the guests ordered scrambled an omelet.

Now consider the following universal variations on (8)-(10):

(11) Every student of mine can write a haiku or play the Moonlight Sonata.

$\sim$ Every student of mine can write a haiku.

$\sim$ Every student of mine can play the Moonlight Sonata.

(12) If things had turned out differently, everyone in my department could have been a banker or a lawyer.

$\leadsto$ Everyone in my department could have been a banker.

$\sim$ Everyone in my department could have been a lawyer.

(13) Every day of the week, some of the guests order scrambled eggs or an omelet.

$\sim$ Every day of the week, some of the guests order scrambled eggs.

$\sim$ Every day of the week, some of the guests order an omelet.

According to our intuitions, these inferences are clearly less robust than the ones in (8)-(10). Needless to say, we would be the last to suggest that this is knock-down evidence against the generality of Chemla's finding, and the 
first to agree that more experimental data are needed. Pending such data, however, we are not convinced that Chemla's result is representative of free choice inferences in general.

Lastly, we would like to argue that there is a perfectly good pragmatic way of explaining the seemingly embedded free choice inference that was so strongly endorsed by Chemla's subjects:

(14) Everybody is allowed to take Algebra or Literature.

$\leadsto$ Everybody can choose which of the two they will take. $(=(5 b))$

Chemla is surely right that this inference cannot be explained by prefixing an $\mathbf{O}$-operator to the sentence, regardless how $\mathbf{O}$ is interpreted, which is to say that a "globalist" explanation will not be forthcoming. But as we have argued above, globalism à la Chemla is a rather restricted doctrine, and should not be equated with Gricean pragmatics. Here is how a Gricean explanation might go. Suppose Inspector Ambrose addresses constables Bacon and Champion as follows:

(15) You can have a daiquiri.

When construed collectively, (15) implies that Bacon and Champion can share a daiquiri between them, but let's put this reading aside, and concentrate on the distributive interpretation, on which Ambrose's intention is that Bacon and Champion each can have a daiquiri. There are various ways of characterizing this interpretation, but one that seems particularly plausible to us is that, when thus understood, Ambrose uses (15) to perform two speech acts rather than one: Bacon is told that he can have a daiquiri and Champion is told the same thing. If this is on the right track, it is obvious how Bacon and Champion might interpret (16) as implying that each of them can choose between a daiquiri and a piña colada, even if Ambrose addressed them as a pair:

(16) $\mathrm{You}_{[\text {plu] }}$ can have a daiquiri or a piña colada.

Similarly, the professor in Chemla's scenario who addressed his students with (14) would be understood as telling each student:

(17) $\mathrm{You}_{[\text {[sing] }}$ can take Algebra or Literature.

Hence, all we need is a Gricean account of free choice permission in the singular, for which see, e.g., Schulz (2005) or Geurts (to appear). 
Free choice for all: a response to Emmanuel Chemla

\section{References}

Chemla, Emmanuel. 2009. Universal implicatures and free choice effects: Experimental data. Semantics and Pragmatics 2(2). 1-33. doi:10.3765/sp.2.2. Chierchia, Gennaro. 2006. Broaden your views: Implicatures of domain widening and the "logicality" of language. Linguistic Inquiry 37(4). 535590. doi:10.1162/ling.2006.37.4.535.

Chierchia, Gennaro, Danny Fox \& Benjamin Spector. To appear. The grammatical view of scalar implicatures and the relationship between semantics and pragmatics. In Claudia Maienborn, Klaus von Heusinger \& Paul Portner (eds.), Handbook of semantics. Mouton de Gruyter.

Eckardt, Regine. 2007. Licensing “or”. In Ulrich Sauerland \& Penka Stateva (eds.), Presupposition and implicature in compositional semantics, 34-70. Houndmills, Basingstoke: Palgrave Macmillan.

Fox, Danny. 2007. Free choice and the theory of scalar implicatures. In Uli Sauerland \& Penka Stateva (eds.), Presupposition and implicature in compositional semantics, 71-120. Houndmills, Basingstoke: Palgrave Macmillan.

Gazdar, Gerald. 1979. Pragmatics: Implicature, presupposition, and logical form. New York: Academic Press.

Geurts, Bart. to appear. Quantity implicatures. Cambridge University Press.

Geurts, Bart \& Nausicaa Pouscoulous. 2009. Embedded implicatures?!? Semantics and Pragmatics 2(4). 1-34. doi:10.3765/sp.2.4.

Groenendijk, Jeroen \& Martin Stokhof. 1984. Studies on the semantics of questions and the pragmatics of answers. Doctoral dissertation, University of Amsterdam.

Klinedinst, Nathan. 2007. Plurals, possibilities, and conjunctive disjunction. UCL Working Papers in Linguistics 19. 261-284.

Schulz, Katrin. 2005. A pragmatic solution for the paradox of free choice permission. Synthese 147(2). 343-377. doi:10.1007/s11229-005-1353-y.

Schulz, Katrin \& Robert van Rooij. 2006. Pragmatic meaning and nonmonotonic reasoning: the case of exhaustive interpretation. Linguistics and Philosophy 29. 205-250. doi:10.1007/s10988-005-3760-4.

Spector, Benjamin. 2006. Aspects de la pragmatique des opérateurs logiques. Doctoral dissertation, University of Paris VII.

Spector, Benjamin. 2007. Aspects of the pragmatics of plural morphology: on higher-order implicatures. In Uli Sauerland \& Penka Stateva (eds.), Presupposition and implicature in compositional semantics, 243-281. Houndmills, Basingstoke: Palgrave Macmillan. 
Bart Geurts \& Nausicaa Pouscoulous

Szabolcsi, Anna \& Bill Haddican. 2004. Conjunction meets negation: a study in cross-linguistic variation. Journal of Semantics 21(3). 219-249. doi:10.1093/jos/21.3.219.

\author{
Bart Geurts \\ Philosophy Department \\ University of Nijmegen \\ P.O. Box 9103 \\ 6500 HD Nijmegen \\ The Netherlands \\ bart.geurts@phil.ru.nl \\ ncs.ruhosting.nl/bart
}

\author{
Nausicaa Pouscoulous \\ Division of Psychology and Language \\ Sciences \\ University College London \\ Chandler House \\ 2 Wakefield Street \\ London $\mathrm{WC}_{1} \mathrm{~N}_{1} \mathrm{PF}$ \\ United Kingdom \\ n.pouscoulous@ucl.ac.uk
}

